\title{
Can we usefully stratify patients according to suicide risk?
}

\author{
Matthew Michael Large conjoint professor ${ }^{1}$, Christopher James Ryan clinical associate professor ${ }^{2}$, \\ Gregory Carter conjoint professor ${ }^{3}$, Nav Kapur professor ${ }^{4}$
}

${ }^{1}$ School of Psychiatry, University of New South Wales, NSW, Australia; ${ }^{2}$ Discipline of Psychiatry, Westmead Clinical School and Sydney Health Ethics, University of Sydney, Australia; ${ }^{3}$ Centre for Brain and Mental Health, Faculty of Health and Medicine, University of Newcastle,; ${ }^{4}$ Centre for Suicide Prevention, Manchester Academic Health. Science Centre, University of Manchester, \& Greater Manchester Mental Health NHS Foundation Trust, Manchester, UK

In the UK, one in five adults has considered suicide at some time, and one in 15 has attempted suicide. ${ }^{1}$ Half of those who attempt suicide seek help afterwards-a quarter from a GP, a quarter from a hospital or specialist medical or psychiatric service. ${ }^{1}$ Suicidal patients; patients who present to health services with suicidal ideas, self harm, or suicide attempts; and patients who present as significantly distressed or mentally ill can be challenging to manage. Doctors are often advised to use suicide risk assessment to help them decide management plans. A wide variety of risk factors have been implicated in the stratification of potentially suicidal patients. ${ }^{2}$ This stratification is often expressed in terms of high, medium, or low-risk. ${ }^{34}$ In practice, doctors commonly give the greatest importance to suicidal ideation. ${ }^{56}$ In some specialist mental health settings these judgments are aided by local risk assessment forms composed of lists of clinical and demographic factors, while other centres use risk strata derived from validated questionnaires or scales. ${ }^{7}$ However, there is little consensus over their use and virtually no evidence that any of the method of suicide risk stratification can contribute to suicide prevention. ${ }^{8}$

\section{What is the evidence of the uncertainty?}

\section{Statistical challenges in risk stratifying suicidal patients}

Although suicidal ideation and suicide attempts are quite common, the rate of death by suicide in the community is only about one in 10000 per annum. $^{9}$ A method that could identify a substantial proportion of future suicides without too many false positives would provide a useful focus for suicide prevention strategies and communication with patients and their families.
Probably the most important single measure of the accuracy of a suicide risk assessment is its positive predictive value (PPV). ${ }^{10}$ PPV is the probability that a patient in the "high risk" stratum will go on to die by suicide. PPV is important because it defines the number of false positive cases who must be treated in order to treat each true positive. Unfortunately, the combination of the modest strength of the statistical association between being a high risk patient and suicide, and the low base rate of suicide places a ceiling on the PPV. This ceiling has made clinicians uncertain of the benefit of risk stratification.

\section{Review of recent meta-analyses}

We identified seven recent and relevant meta-analyses (table $1 \Downarrow) .{ }^{11-17}$ Almost all of the primary research synthesised by the seven studies was conducted among psychiatric patients or people presenting with self harm. Six of the seven meta-analyses can be regarded as of high quality because they adhered to Preferred Reporting Items for Systematic Reviews and Meta-Analyses (PRISMA) guidelines. ${ }^{18}$

\section{Individual risk factors for suicide}

None of the meta-analyses found that any individual clinical risk factor, ${ }^{14}{ }^{16}$ including suicide thoughts and behaviours, ${ }^{11}{ }^{12}$ was sufficiently accurate to be useful as the basis to allocate interventions. One meta-analyses estimated that the absolute risk for suicide of those with suicidal ideation was about $1 \%$ over a year $(1.4 \%$ in psychiatric patients and $0.23 \%$ in non-psychiatric patients). ${ }^{15}$ 


\section{What you need to know}

- Despite the ubiquity of advice to use suicide risk assessment in clinical practice, there is no evidence that these assessments can usefully guide decision making

- All patients presenting with a mental health problem require a thorough and sympathetic assessment with the aim of negotiating an individualised treatment plan

- All patients with suicidal thoughts or behaviours should be offered evidence based therapies for the treatable problems associated with suicide, such as substance misuse disorder and depression

- The overwhelming majority of people who might be viewed as at high risk of suicide will not die by suicide, and about half of all suicides will occur among people who would be viewed as low risk

\section{Sources and selection criteria}

We searched PubMed using the terms "suicid* [title] AND meta-analysis" for articles published in English between 1 June 2012 and 1 June 2017 that reported a quantitative synthesis of primary research that examined the association between suicide and (a) suicide thoughts and behaviours and other suicide risk factors; $(b)$ experimental models of suicide risk; and $(c)$ suicide risk scales, among adults in psychiatric or non-psychiatric settings. Although we looked for meta-analyses with broad inclusion criteria, most of the primary research concerned psychiatric inpatients, outpatients, or those presenting with self harm or suicide attempts.

We excluded meta-analyses that exclusively examined a particular clinical risk factor other than suicide thoughts and behaviours, or exclusively examined biological risk factors for suicide. We also excluded meta-analyses that exclusively examined the association between risk factors and suicide among patients with a specific medical or psychiatric disorder.

The searches yielded 199 titles. Twelve papers were examined and seven meta-analyses were identified as relevant to this article.

\section{Risk stratification by combining risk factors}

Three meta-analyses included primary research that characterised some patients as high risk based on the presence of a combination of clinical and demographic factors. ${ }^{13-17}$ The studies either expressed the higher risk as an odds ratio, hazard ratio, or risk ratio, or reported the absolute proportion of high risk patients going on to die by suicide (expressed as positive predictive value) or did both (table $1 \Downarrow$ ). Two meta-analyses found that $5 \%$ of high risk patients will die by suicide in the long term, ${ }^{13}{ }^{17}$ a proportion that is very similar to the long term suicide risk associated with severe psychiatric disorders such as schizophrenia ${ }^{19}$ and affective disorders. ${ }^{20}$ No high risk determination, whether based on a model that integrated multiple risk factors ${ }^{13}$ or a suicide risk scale ${ }^{13}{ }^{14}$ was strongly associated with later death by suicide. Moreover, almost half of all patients who die by suicide come from lower risk strata, indicating a low sensitivity in high risk status. ${ }^{13}$

\section{Is ongoing research likely to provide relevant evidence?}

Two of the meta-analyses specifically examined whether the predictive strength of risk assessment had improved over recent decades: both found it had not. ${ }^{13}{ }^{16} \mathrm{We}$ also searched the International Clinical Trials Registry ${ }^{21}$ and the International Register of Systematic Reviews ${ }^{22}$ and found no evidence of any relevant upcoming trial testing the ability of risk stratification to reduce suicide or any relevant systematic review.

Incremental improvement in risk stratification might occur if there is identification of previously unknown risk factors, ${ }^{23}$ or new ways of combining established risk factors with methods derived from artificial intelligence research. ${ }^{24}$ But to be useful to a clinician, new methods of suicide risk stratification would need to be several orders of magnitude more powerful than the existing methods. Future research might also concentrate on suicide among primary care patients or the general population. However, while it is possible that suicide risk assessment might have a greater power of discrimination in these populations, the much lower base rate of suicide will place similar limits on the positive predictive value and clinical utility of higher risk strata.

\section{What should we do in the light of the uncertainty?}

Do not subject people who present with mental illness or psychological distress to an assessment that attempts to stratify them into groups considered to be at higher or lower risk of suicide. While suicide risk stratification does provide some prognostic information in a statistical sense, it does not provide enough information about the likelihood of future suicide to guide clinical practice. The low positive predictive value of risk stratification means that most people who receive a treatment because of their high risk status will never die by suicide, and the limited sensitivity means that some low risk patients, who will die by suicide, might be deprived of treatment options.

Instead focus the assessment on the content and nature of the communication between the patient and the doctor and the opportunity to address what the patient needs (box 2). This involves identifying common modifiable social and clinical factors for suicide and then addressing them in an individually negotiated treatment plan. Most modifiable factors require treatment in their own right-for example, assisting a person with depression or substance misuse. This is an approach to management based on the patient's current treatment needs and not on clinicians' perceptions of their future suicide risk. Such a needs based approach should involve offering evidence based treatments for a wide variety of common social and clinical problems including any mental disorder, alcohol and drug misuse, relationship difficulties, employment and accommodation problems. It also necessitates addressing the individual circumstances that are distressing the patient.

Assessment should be intrinsically helpful. Use active listening, be respectful, thorough, and sympathetic. Do not dismiss any patient who raises concerns of suicide as being at low risk. Use each assessment as a dialogue, first with the patient and then with his or her family or friends. Offer every patient an individualised treatment plan based on his or her needs and preferences. Reserve psychiatric admission for situations when treatment in a less restrictive setting is not wanted by the patient or is just not feasible. Some patients will have access to lethal suicide methods. Restriction of lethal suicide methods is one of the most well accepted interventions to reduce suicide and should be addressed with every patient irrespective of perceptions of suicide risk. Agree a treatment plan with every 


\section{Box 2: How to approach a patient who you think might be suicidal}

- Conduct a respectful, thorough, and sympathetic assessment using active listening

- Keep a focus on the content and nature of the doctor-patient interaction

- Try to understand and address the individual circumstances that are distressing the patient

- Identify the patient's current treatment needs, including common modifiable social and clinical factors for suicide

- Do not attempt to stratify patients into high and low risk categories

- Do not simply rely on the patient's expression or non-expression of suicide plans and ideas

- Never dismiss any patient who raises your concern about suicide as low risk

- Talk with the patient's family or friends

- Ask about firearms and other lethal methods of methods of suicide

- Involuntary hospitalisation should be used sparingly and with great care

- Negotiate a management plan with every patient

- Document your assessment, reasoning, and treatment plan

patient with suicide thoughts. Don't let anyone go home without some action agreed.

Competing interests: We have read and understood BMJ policy on declaration of interests and declare the following interests. MML and CJR have provided evidence in coroner's inquiries and other legal matters after suicides. NK chaired the NICE guidelines on the management of self harm and currently sits on the NICE suicide prevention guideline group and the Department of Health (England) National Suicide Prevention Advisory Group. GC chaired and MML was an author for the Royal Australian and New Zealand College of Psychiatrists deliberate self harm clinical practice guidelines. The views expressed here are those of the authors and not those of NICE or the Department of Health (England) or the Royal Australian and New Zealand College of Psychiatrists

Provenance and peer review: Commissioned; externally peer reviewed.

1 McManus S, Hassiotis A, Jenkins R, et al. Suicidal thoughts, suicide attempts, and self-harm. Adult Psychiatric Morbidity Survey 2014. NHS digital, 2016. http://content. digital.nhs.uk/catalogue/PUB21748/apms-2014-suicide.pdf.

2 Turecki G, Brent DA. Suicide and suicidal behaviour. Lancet 2016;359:1227-39. doi:10. 1016/S0140-6736(15)00234-2 pmid:26385066.

3 Betz ME, Boudreaux ED. Managing suicidal patients in the emergency department. Ann Emerg Med 2016;359:276-82. doi:10.1016/j.annemergmed.2015.09.001 pmid:26443554. Sinclair L, Leach R. Exploring thoughts of suicide. BMJ 2017;359:j1128. doi:10.1136/bmj. j1128 pmid:28360192.

5 Tanguturi Y, Bodic M, Taub A, Homel P, Jacob T. Suicide risk assessment by residents: deficiencies of documentation. Acad Psychiatry 2017;359:513-9. doi:10.1007/s40596016-0644-6 pmid:28083763.

6 Morgan HG, Stanton R. Suicide among psychiatric in-patients in a changing clinical scene. Suicidal ideation as a paramount index of short-term risk. Br J Psychiatry 1997;359:561-3. doi:10.1192/bjp.171.6.561 pmid:9519097.

7 Quinlivan L, Cooper J, Steeg S, et al. Scales for predicting risk following self-harm: an observational study in 32 hospitals in England. BMJ Open 2014;359:e004732. doi:10. 1136/bmjopen-2013-004732 pmid:24793255.

8 Wand T. Investigating the evidence for the effectiveness of risk assessment in mental health care. Issues Ment Health Nurs 2012;359:2-7. doi:10.3109/01612840.2011. 616984 pmid:22224960.

9 Office of National Statistics. Suicides in the UK: 2015 registrations 2017 www.ons.gov. uk/peoplepopulationandcommunity/birthsdeathsandmarriages/deaths/bulletins/ suicidesintheunitedkingdom/2015registrations.
10 Szmukler G, Everitt B, Leese M. Risk assessment and receiver operating characteristic curves. Psychol Med 2012;359:895-8. doi:10.1017/S003329171100208X pmid:22017918. 11 Chapman CL, Mullin K, Ryan CJ, Kuffel A, Nielssen O, Large MM. Meta-analysis of the association between suicidal ideation and later suicide among patients with either a schizophrenia spectrum psychosis or a mood disorder. Acta Psychiatr Scand 2015:359:162-73. doi:10.1111/acps.12359 pmid:25358861.

12 Ribeiro JD, Franklin JC, Fox KR, et al. Self-injurious thoughts and behaviors as risk factors for future suicide ideation, attempts, and death: a meta-analysis of longitudinal studies. Psychol Med 2016;359:225-36. doi:10.1017/S0033291715001804 pmid:26370729.

13 Large M, Kaneson M, Myles N, Myles H, Gunaratne P, Ryan C. Meta-analysis of longitudinal cohort studies of suicide risk assessment among psychiatric patients: heterogeneity in results and lack of improvement over time. PLoS One 2016;359:e0156322 doi:10.1371/journal.pone.0156322 pmid:27285387.

14 Chan MK, Bhatti H, Meader N, et al. Predicting suicide following self-harm: systematic review of risk factors and risk scales. Br J Psychiatry 2016;359:277-83. doi:10.1192/bjp. bp.115.170050 pmid:27340111.

15 Hubers AA, Moaddine S, Peersmann SH, et al. Suicidal ideation and subsequent completed suicide in both psychiatric and non-psychiatric populations: a meta-analysis. Epidemiol Psychiatr Sci 2016:1-13. doi:10.1017/S2045796016001049 pmid:27989254.

16 Franklin JC, Ribeiro JD, Fox KR, et al. Risk factors for suicidal thoughts and behaviors: A meta-analysis of 50 years of research. Psychol Bull 2017;359:187-232. doi:10.1037/ bul0000084 pmid:27841450.

17 Carter G, Milner A, McGill K, Pirkis J, Kapur N, Spittal MJ. Predicting suicidal behaviours using clinical instruments: systematic review and meta-analysis of positive predictive values for risk scales. Br J Psychiatry 2017;359:387-95. doi:10.1192/bjp.bp.116. 182717 pmid:28302700.

18 Moher D, Liberati A, Tetzlaff J, Altman DG. PRISMA Group. Preferred reporting items for systematic reviews and meta-analyses: the PRISMA statement. J Clin Epidemiol 2009:359:1006-12. doi:10.1016/.j.jlinepi.2009.06.005 pmid:19631508.

19 Palmer BA, Pankratz VS, Bostwick JM. The lifetime risk of suicide in schizophrenia: a reexamination. Arch Gen Psychiatry 2005;359:247-53. doi:10.1001/archpsyc.62.3. 247 pmid: 15753237.

20 Bostwick JM, Pankratz VS. Affective disorders and suicide risk: a reexamination. Am J Psychiatry 2000;359:1925-32. doi:10.1176/appi.ajp.157.12.1925 pmid:11097952.

21 World Health Organization. International Clinical Trials Registry Platform. Version 3.3. http://apps.who.int/trialsearch/default.aspx.

22 NHS National Institute for Health Research. PROSPERO: international prospective register of systematic reviews. http://apps.who.int/trialsearch/default.aspx.

23 Bolton JM, Gunnell D, Turecki G. Suicide risk assessment and intervention in people with mental illness. BMJ 2015;359:h4978. doi:10.1136/bmj.h4978 pmid:26552947.

24 Kessler RC, Warner $\mathrm{CH}$, Ivany $\mathrm{C}$, et al. Army STARRS Collaborators. Predicting suicides after psychiatric hospitalization in US Army soldiers: the army study to assess risk and resilience in servicemembers (Army STARRS). JAMA Psychiatry 2015;359:49-57. doi: 10.1001/jamapsychiatry.2014.1754 pmid:25390793.

Published by the BMJ Publishing Group Limited. For permission to use (where not already granted under a licence) please go to http://group.bmj.com/group/rights-licensing/ permissions 


\section{Education into practice}

- How do you currently identify patients at risk of suicide?

- How has this article changed the way you will approach conversations with patients who you suspect may be at risk of suicide?

- How will you follow up patients who you suspect may be at risk of suicide?

\section{What patients need to know}

If you present to clinical services with suicidal thoughts or behaviours you should

- Expect a thorough and respectful assessment of your situation and needs

- Have the opportunity to explain the nature and extent of your suicidal ideation without undue fear of unwarranted restrictive interventions

- Expect that your treatment preferences and needs will be foremost in the doctor's mind.

\section{How patients were involved in the creation of this manuscript}

Four patients with a history of suicidal thoughts or behaviours provided written feedback on a draft of the manuscript. Some alterations were made in response to their suggestions. All four patients were critical of suicide risk stratification and strongly supported individualised assessments leading to treatment plans based on their preferences and needs.

\section{Table}

Table 1| Meta-analyses examining the association between suicidal thoughts and behaviours, clinical risk factors, suicide risk scales, and high risk models for future suicide among adults

\begin{tabular}{|c|c|c|c|c|c|c|}
\hline Study & Research question & Population & $\begin{array}{c}\text { No of } \\
\text { included } \\
\text { studies }\end{array}$ & Outcomes & $\begin{array}{c}\text { Meta-analysis } \\
\text { guideline }\end{array}$ & Authors' conclusions \\
\hline $\begin{array}{l}\text { Chapman et } \\
\text { al } 2104^{11}\end{array}$ & $\begin{array}{l}\text { Association between } \\
\text { suicide ideas and suicide } \\
\text { according to diagnosis }\end{array}$ & $\begin{array}{l}\text { Cohort and case control } \\
\text { studies reporting suicidal } \\
\text { ideation and suicide among } \\
\text { those with mood or } \\
\text { schizophrenia spectrum } \\
\text { disorders }\end{array}$ & 25 & $\begin{array}{l}\text { Patients with mood disorders: } \\
\text { OR } 1.49 \text { ( } 95 \% \mathrm{Cl} 0.92 \text { to } 2.42) \text {. } \\
\text { Patients with schizophrenia } \\
\text { spectrum disorders: OR } 6.49 \\
\text { (3.82 to } 11.02)\end{array}$ & PRISMA & $\begin{array}{l}\text { Association between suicidal } \\
\text { ideation and suicide is } \\
\text { mediated by diagnosis and } \\
\text { might not be statistically } \\
\text { significant among patients with } \\
\text { mood disorders }\end{array}$ \\
\hline $\begin{array}{l}\text { Ribeiro et al } \\
2016^{12}\end{array}$ & $\begin{array}{l}\text { Magnitude and clinical } \\
\text { utility of associations } \\
\text { between self injurious } \\
\text { thoughts and behaviours } \\
\text { and suicide }\end{array}$ & $\begin{array}{l}\text { Longitudinal studies that } \\
\text { examined a discrete suicide } \\
\text { risk factor conducted in any } \\
\text { population year or geographic } \\
\text { location }\end{array}$ & 144 & $\begin{array}{l}\text { Suicidal ideation: OR } 1.95 \text { (1.31 } \\
\text { to } 2.90) \text {. } \\
\text { Suicide plans: OR } 1.44 \text { (1.11 to } \\
1.86) \text {. } \\
\text { Suicide attempt: OR } 2.03 \text { (1.61 } \\
\text { to } 2.57)\end{array}$ & PRISMA & $\begin{array}{c}\text { Self injurious thoughts and } \\
\text { behaviours provide only } \\
\text { marginal improvement in } \\
\text { diagnostic accuracy above } \\
\text { chance }\end{array}$ \\
\hline $\begin{array}{l}\text { Large et al } \\
2016^{13}\end{array}$ & $\begin{array}{c}\text { Association of a high risk } \\
\text { categorisation with } \\
\text { suicide }\end{array}$ & $\begin{array}{l}\text { Longitudinal cohort studies of } \\
\text { psychiatric patients (receiving } \\
\text { inpatient or outpatient } \\
\text { treatment, or those assessed } \\
\text { after self harm or suicide } \\
\text { attempt) }\end{array}$ & 37 & $\begin{array}{c}\text { Validation studies of suicide risk } \\
\text { scales: OR } 4.68 \text { (2.97 to } 7.40 \text { ). } \\
\text { Exploratory studies: OR } 5.13 \\
\text { (3.57 to } 8.88) \\
\text { Pooled sensitivity } 56 \% \text {, } \\
\text { specificity } 79 \% \text {, PPV } 5.5 \%\end{array}$ & PRISMA & $\begin{array}{l}\text { A statistically strong and } \\
\text { reliable method to distinguish } \\
\text { patients with a high risk of } \\
\text { suicide remains elusive }\end{array}$ \\
\hline $\begin{array}{l}\text { Chan et al } \\
2016^{14}\end{array}$ & $\begin{array}{c}\text { Association between } \\
\text { selected risk factors and } \\
\text { selected risk scales and } \\
\text { suicide }\end{array}$ & $\begin{array}{l}\text { Prospective cohort studies of } \\
\text { suicide among patients } \\
\text { presenting with self harm }\end{array}$ & 19 & $\begin{array}{c}\text { Previous self harm: HR } 1.68 \\
\text { (1.38 to } 2.05) \text {. } \\
\text { Suicidal intent: HR } 2.70 \text { (1.91 to } \\
3.81) \text {. } \\
\text { Physical health problems: HR } \\
1.99 \text { (1.16 to } 3.43) \text {. } \\
\text { Male sex: HR } 2.05 \text { ( } 1.70 \text { to } 2.46) \text {. } \\
\text { Suicide risk scales, pooled } \\
\text { sensitivity } 80 \% \text {, specificity } 46 \% \text {, } \\
\text { PPV } 1.3-16.7 \%\end{array}$ & PRISMA & $\begin{array}{l}\text { Use of suicide risk scales or } \\
\text { overreliance on risk factors } \\
\text { may provide false reassurance } \\
\text { and is clinically dangerous. No } \\
\text { scales have sufficient evidence } \\
\text { to support their use }\end{array}$ \\
\hline $\begin{array}{l}\text { Hubers et al } \\
2016^{15}\end{array}$ & $\begin{array}{l}\text { Association of suicidal } \\
\text { ideation and suicide in } \\
\text { psychiatric and } \\
\text { non-psychiatric } \\
\text { populations }\end{array}$ & $\begin{array}{c}\text { Cohort and case control } \\
\text { studies reporting suicide } \\
\text { among those with and without } \\
\text { suicidal ideation. }\end{array}$ & 81 & $\begin{array}{c}\text { Psychiatric populations: RR } 3.53 \\
\text { (2.81 to } 4.44) \text {. PPV in one year } \\
1.40 \% \text {. } \\
\text { Non-psychiatric populations: RR } \\
6.61 \text { (4.62 to } 9.47) \text {. PPV in one } \\
\text { year } 0.41 \%\end{array}$ & Not stated. & $\begin{array}{l}\text { Absolute risks of suicide (PPV) } \\
\text { are more essential than } \\
\text { relative risks, and any suicide } \\
\text { ideation should prompt } \\
\text { secondary prevention } \\
\text { strategies }\end{array}$ \\
\hline
\end{tabular}


Table 1 (continued)

\begin{tabular}{|c|c|c|c|c|c|c|}
\hline Study & Research question & Population & $\begin{array}{c}\text { No of } \\
\text { included } \\
\text { studies }\end{array}$ & Outcomes & $\begin{array}{l}\text { Meta-analysis } \\
\text { guideline }\end{array}$ & Authors' conclusions \\
\hline $\begin{array}{l}\text { Franklin et } \\
\text { al } 2017^{16}\end{array}$ & $\begin{array}{l}\text { To examine predictors of } \\
\text { suicidal behaviours }\end{array}$ & $\begin{array}{l}\text { Longitudinal studies providing } \\
\text { effect size data for the } \\
\text { relationship between risk } \\
\text { factors and suicide }\end{array}$ & 365 & $\begin{array}{c}\text { Pooled risk factors: OR } 1.64 \\
\text { (1.53 to } 1.76) \text {; HR } 1.66 \text { ( } 1.59 \text { to } \\
\text { 1.74). Pooled sensitivity } 9 \% \text {, } \\
\text { specificity } 81 \%\end{array}$ & PRISMA & $\begin{array}{l}\text { Prediction only slightly better } \\
\text { than chance for all outcomes }\end{array}$ \\
\hline $\begin{array}{l}\text { Carter et al } \\
2017^{17}\end{array}$ & $\begin{array}{c}\text { Positive predictive values } \\
\text { of suicide risk } \\
\text { assessment instruments } \\
\text { for suicide and suicidal } \\
\text { behaviours }\end{array}$ & $\begin{array}{l}\text { Longitudinal studies of } \\
\text { psychological or biological } \\
\text { tests to classify participants as } \\
\text { high risk and suicide mortality }\end{array}$ & 70 & PPV 5.5\% & PRISMA & $\begin{array}{c}\text { No high risk classification was } \\
\text { clinically useful }\end{array}$ \\
\hline
\end{tabular}

$\mathrm{OR}=\mathrm{odds}$ ratio. $\mathrm{HR}=$ hazard ratio. $\mathrm{RR}=$ risk ratio. $\mathrm{PPV}=$ positive predictive value. 